\title{
Prevalência de Cryptococcus neoformans nos pombos urbanos da cidade de Porto Alegre, Rio Grande do Sul
}

\author{
Prevalence of Cryptococcus neoformans in urban pigeons of Porto Alegre (RS), Brazil
}

Aline Reolon'; Leandro Reus Rodrigues Perez'; Adelina Mezzari²

\begin{abstract}
unitermos resumo
Cryptococcus neoformans

Pombos

Fontes saprofiticas

Criptococose

Cryptococcus neoformans, levedura encapsulada, é o agente etiológico da criptococose em humanos e animais. A variedade neoformans, encontrada em fontes ambientais, incluindo fezes de pombos, é importante causa de mortalidade em indivíduos imunodeprimidos em todo o mundo. Contudo, ainda não há estudos sobre sua ecologia na cidade de Porto Alegre, onde se tem registro da ocorrência de casos humanos dessa micose. Para pesquisar fontes saprofíticas de C. neoformans na cidade de Porto Alegre, foram coletadas 88 amostras de excretas de pombos em distintas praças da cidade. Suspensões das amostras em salina estéril foram semeadas em placas com meio ágar Sabouraud e incubadas em estufa a temperaturas entre 29 e $30,5^{\circ} \mathrm{C}$. Após cinco dias, colônias mucóides foram subcultivadas para identificação através de provas morfofisiológicas. O fungo C. neoformans foi isolado em 88 (100\%) das amostras avaliadas, confirmando sua ocorrência nos pombos que habitam as praças da cidade.
\end{abstract}

abstract

Cryptococcus neoformans is an encapsulated yeast, causing cryptococcosis in human beings and animals. The variety neoformans, found in environmental sources, including pigeon excrements, is an important cause of mortality in immunocompromised individuals in the whole world. However, there are still no studies on its ecology in the city of Porto Alegre, where register of the occurrence of human cases of this mycosis is found. To study the saprophitic sources of $C$. neoformans in the city of Porto Alegre, 88 samples of avian excreta have been collected in distinct squares. Suspension of the samples in sterile saline solution had been planted in plates with Sabouraud agar and incubated in stove at $29-30.5^{\circ} \mathrm{C}$. After five days mucoid colonies were subcultived for identification through morphologic and physiologic tests. C. neoformans was isolated in 88 (100\%) of the samples, proving its occurrence in the pigeons that inhabit the squares of that city. key words Cryptococcus neoformans Pigeon

Saprophitic source

Cryptococcosis

\section{Introdução}

O Cryptococcus neoformans é a forma assexuada do basidiomiceto Filobasidiella neoformans, levedura encapsulada de grande importância na micologia médica por ser agente etiológico da criptococose. Esse fungo apresenta na sua estrutura microbiológica cápsula de polissacarídeos que lhe confere antigenicidade.
O C. neoformans apresenta os sorotipos A, B, C, D e $A D$, distribuídos em três variedades: $C$. neoformans var. neoformans (sorotipos $A, A D, D), C$. neoformans var. gattii (sorotipos $\mathrm{B}, \mathrm{C})^{(14,15,18)}$ e $\mathrm{C}$. neoformans var. grubii (sorotipo $A)^{(6)}$ que diferem em aspectos bioquímicos, ecológicos, antigênicos e genéticos. Cepas sorotipo

1. Aluno da Faculdade de Farmácia da Universidade Federal do Rio Grande do Sul (UFRCS).

2. Professora da Faculdade de Farmácia da UFRCS e da Fundação Faculdade Federal de Ciências Médicas de Porto Alegre. 
AD de C. neoformans são raramente cepas aneuplóides ou diplóides que resultam de troca entre cepas com sorotipos A e $D^{(18)}$. Esses antígenos capsulares podem estar presentes no liquor, no plasma ou na urina e são detectados mediante técnicas de aglutinação em látex. A variedade neoformans tem distribuição cosmopolita relacionada a solos contaminados naturalmente com excretas de aves ${ }^{(9-11,27-29)}$. A principal fonte de contaminação do fungo nos seres humanos são as fezes de pombos, onde o fungo permanece viável para contágio por um período de até dois anos. Essa variedade tem a capacidade de colonizar a mucosa do papo dos pombos sem causar doença, sendo um parasita natural dessas aves. A universalidade e a peculiar adaptação dos pombos aos centros urbanos relacionam-se com a ubiqüidade desse agente fúngico, que é facilmente isolado de fontes ambientais, inclusive de poeira domiciliar ${ }^{(21,22)}$. A infecção por $C$. neoformans var. neoformans é adquirida através da inalação dos propágulos do ambiente, na forma de leveduras, menores que $2 \mu \mathrm{m}$ de diâmetro ${ }^{(31)}$.

Lazéra et al. verificaram a presença do $C$. neoformans var. neoformans na madeira em decomposição e em árvores, sugerindo um novo hábitat natural e um possível nicho ecológico primário para o fungo ${ }^{(16,17)}$.

O C. neoformans var. neoformans, como agente oportunista ${ }^{(30)}$, infecta hospedeiros imunodeficientes. $\mathrm{O}$ aumento populacional desses indivíduos com doenças como a síndrome da imunodeficiência adquirida (AIDS), leucêmicos, transplantados, portadores de tumores e pacientes em uso prolongado de corticóides e antibióticos tem aumentado o número de casos de criptococose ${ }^{(25)}$.

A variedade gattii é observada nas regiões tropicais e subtropicais, sendo um patógeno primário que acomete hospedeiros imunocompetentes ${ }^{(14,26)}$. Inicialmente era encontrado em Eucalyptus camaldulensis na Austrália ${ }^{(7)}$, e posteriormente em restos vegetais de outras espécies de eucaliptos em diferentes países. No Brasil, o C. neoformans variedades gattii foi também encontrado em cássia rosa (Cassia grandis), fícus (Ficus microcarpa) e outros, evidenciando outros hábitats naturais para essa variedade.

No ano de 1998 a variedade grubii foi reconhecida ${ }^{(4)}$, sendo encontrada em quase todos os relatos de casos associados à AIDS nos EUA. No entanto, a variedade grubii pode ser encontrada em pacientes imunodeficientes, alguns indivíduos hígidos, fontes veterinárias, fezes de pássaros, substratos como sucos de frutas em fermentação, água, madeira, solo e $\operatorname{ar}^{(4)}$.
As variedades neoformans e grubii diferem da variedade gattii nos seus cariótipos eletroforéticos, na amplificação polimórfica do DNA e nas seqüências de rDNA(6).

O Cryptococcus neoformans foi isolado pela primeira vez em 1985, a partir de um suco de frutas em deteriorização. Esse fungo tem em suas características morfológicas o formato esférico ou ovóide de aproximadamente 4 a $12 \mu \mathrm{m}$ de diâmetro e é cercado por uma cápsula espessa de polissacarídeos. Cresce em culturas no meio de ágar Sabouraud à temperatura ambiente $\left(25\right.$ a $\left.37^{\circ} \mathrm{C}\right)$, formando colônias de cor creme, brilhosas e mucóides. Não fermenta carboidratos, mas assimila glicose, maltose, sacarose e galactose. A uréia é por ele hidrolisada. Nos tecidos do hospedeiro, 0 fungo apresenta-se como levedura encapsulada, fato que o torna único entre os fungos patogênicos ${ }^{(8)}$.

Os fatores que induzem a patogenicidade do C. neoformans são divididos em dois grupos: um relacionado às características do estabelecimento de infecção no hospedeiro e capacitação de sobrevivência do parasita no mesmo, e outro relacionado aos fatores de virulência propriamente ditos afetando o grau de patogenicidade.

Para transpor as barreiras existentes no trato respiratório e depositar-se nos alvéolos pulmonares, o microrganismo deve produzir formas viáveis de tamanhos compatíveis com um diâmetro médio menor que $4 \mu \mathrm{m}$. Isso ocorre através da reprodução sexuada, onde há produção de basidiósporos de tamanhos entre 1,8 a $3 \mu \mathrm{m}$. Para o crescimento do fungo nos tecidos do hospedeiro é necessário transpor as condições fisiológicas existentes no sítio de infecção. Ele deve crescer a $37^{\circ} \mathrm{C}$, numa concentração de gás carbônico aproximadamente de $5 \%$ e pH entre 7,3 e 7,4. Para o crescimento a $37^{\circ} \mathrm{C}$, o fungo deve expressar a subunidade catalítica $A$ da proteína calcineurina, fosfatase específica para serinas e treoninas, sendo esta ativada por $\mathrm{Ca}^{+2}$ calmodulina e envolvida na resposta ao estresse do fungo. Essa proteína tem papel fundamental para o crescimento do microrganismo no hospedeiro e é necessária à sua patogenicidade ${ }^{(3)}$.

A cápsula polissacarídica é um fator de virulência do C. neoformans ${ }^{(23)}$. Ela atua na resistência à fagocitose mediada por macrófagos, neutrófilos e monócitos(3), sendo decorrente do potencial zeta negativo dos componentes capsulares, o que provoca repulsão eletrostática. Resulta na diminuição da fagocitose, havendo considerável diminuição da apresentação de antígenos nas células T, acarretando diminuição da resposta imunológica. Essa cápsula também interfere na presença dos componentes do complemento impossibilitando a ligação aos receptores CR3 dos leucócitos e prejudicando a resposta leucocitária( ${ }^{(3)}$. Concentrações 
de bicarbonato e gás carbônico em condições fisiológicas normais humanas também induzem a produção da cápsula. De modo análogo, limitações de ferro levam à intensa elaboração da estrutura capsular por parte do fungo(1).

O C. neoformans é capaz de produzir, em meio de cultura e durante a infecção, o poliol D-manitol. Este manitol pode ser tanto utilizado como secretado pelo C. neoformans. A quantidade desse poliol secretada está relacionada com a quantidade de microorganismos presentes no sítio da infecção, apresentando-se como osmólito ou antioxidante durante o processo da infecção. A produção de manitol pelas células do $C$. neoformans no local da infecção é responsável pelo aumento da resistência ao estresse provocado por choque térmico, diferenças osmóticas, dano por formas reativas de oxigênio e ataque mediado por polimorfonucleares, com conseqüente aumento da patogenicidade ${ }^{(23)}$.

A enzima urease é secretada pelo fungo em condições normais de crescimento tanto no meio ambiente quanto em quadros patológicos. Uma metaloenzima catalisa a hidrólise da uréia a amônia e carbamato. Essa enzima tem importância durante a infecção no pulmão, levando a diferentes respostas teciduais em casos de mutantes não-produtoras de urease $^{(4)}$. Outras enzimas que atuam como fator de virulência no C. neoformans são as proteases. O mecanismo de virulência dessas proteínas é o inicio da invasão dos tecidos do hospedeiro e da destruição das proteínas de cunho imunológico(2). A enzima fosfolipase atua degradando membranas celulares das células do hospedeiro, com conseqüente penetração tecidual(5).

Outra característica do C. neoformans é a capacidade de sintetizar melanina, através de substratos específicos ${ }^{(24)}$. A enzima responsável pela formação de precursores envolvidos na síntese de melanina é uma fenoloxidase intracelular, caracterizada como uma lacase. Essa classe de enzimas pertence à família das oxidases, que tem como co-fator os íons cobre e ferro. A síntese de melanina está condicionada à existência de DOPA exógena, que é transportada para o meio intracelular. Essa melanina criptocócica tem sido observada como um fator de virulência. Localiza-se na parede celular do fungo e confere à célula um efeito protetor contra reações oxidativas, atuando na defesa contra a radiação UV e o ataque das células de defesa ${ }^{(12)}$. A melanina dá proteção à célula fúngica contra as defesas do hospedeiro em função de sua capacidade de reter enzimas hidrolíticas provenientes do fungo próximo à parede celular. Com isso gera a estabilidade das enzimas impedindo que as mesmas sejam degradadas, deixando os produtos da ação dessas enzimas para o microorganismo ${ }^{(13)}$. A melanina do
C. neoformans tem a capacidade de proteger as proteínas do hospedeiro, impedindo que as proteínas microbicidas interfiram na membrana plasmática do fungo e resultem na ação hidrolítica de algumas enzimas ${ }^{(13)}$.

A criptococose tem a forma meningoencefálica como a mais freqüente, sendo fundamental o diagnóstico precoce, para reduzir a morbidade e a letalidade dessa micose.

\section{Material e método}

Foram colhidas 88 amostras de excretas de pombos em cinco praças de Porto Alegre, Rio Grande do Sul. As amostras são raspados de excretas encontradas no solo. Foram colhidas as amostras envelhecidas e secas, e as amostras frescas provenientes de pombos (Columba sp.). Essas amostras foram acondicionadas em frascos plásticos estéreis. $\mathrm{O}$ material foi processado em câmara de fluxo laminar (classe 2-B1). A amostra foi homogeneizada em gral com pistilo de porcelana previamente esterilizado. Cerca de $1 \mathrm{~g}$ do material homogeneizado foi suspenso em $2 \mathrm{ml}$ de solução fisiológica estéril. Após agitação em vórtex por três minutos e repouso por 30 minutos à temperatura ambiente, o sobrenadante foi aspirado e $0,1 \mathrm{ml}$ foi semeado em placa de Petri com meio de ágar Sabouraud. As placas foram incubadas em estufa à temperatura entre 29 e $30,5^{\circ} \mathrm{C}$ e observadas diariamente até sete dias. As colônias lisas, úmidas, brilhantes e de coloração creme a marrom foram repicadas na forma de estrias em placa de ágar Sabouraud para isolamento (Figura 1) e posterior obtenção de subcultivos em tubos contendo ágar Sabouraud 2\%, para a realização da prova de identificação (prova da urease). $\mathrm{O}$ exame direto foi feito em montagens de lâmina com a suspensão das fezes e tinta da China e sobrepondo uma lamínula (Figura 2). A presença de leveduras com formas regulares, globosas, arredondadas, encapsuladas, unibrotantes ou multibrotantes e sem hifas ou pseudo-hifas sugeriu a presença do fungo, por ser a cápsula de polissacarídeos uma estrutura peculiar do C. neoformans e não de outras leveduras, o que permite sua identificação (Figura 2). Foi também estimada numericamente a quantidade de propágulos de C. neoformans existentes em cada amostra positiva através da contagem das colônias com características de $C$. neoformans que se desenvolveram a partir da semeadura de $0,1 \mathrm{ml}$ que é equivalente a $0,05 \mathrm{~g}$ de fezes; essa contagem foi então expressa em unidades formadoras de colônias do fungo por grama de matéria orgânica processada (UFC/g). Posteriormente foi realizado o teste fisiológico da produção de urease (Figura 3) confirmando o crescimento do fungo. 


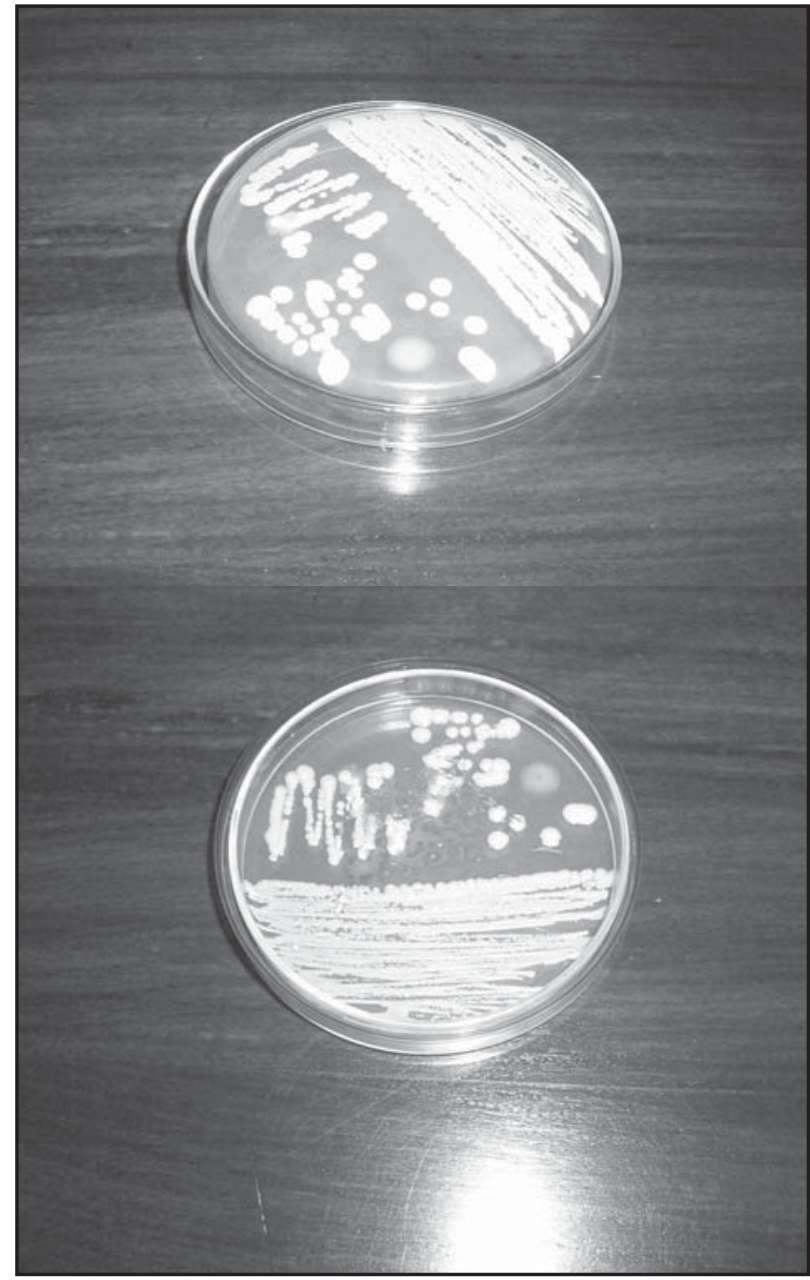

Figura 1 - Crescimento de C. neoformans em placa de ágar Sabouraud, demonstrando 0 isolamento das colônias. A) verso; B) frente da placa

\section{Resultados}

Das 88 amostras analisadas, $100 \%$ foram positivas para Cryptococcus neoformans nos cinco ambientes estudados (Tabela). A contagem das unidades formadoras de colônias (UFC) de C. neoformans foi realizada em todas as amostras positivas (Tabela).

\section{Discussão}

Emmons, no início da década de 1950, já fazia referência às excretas de pombos (Columba livia) como fontes saprofíticas de $C$. neoformans em ambientes urbanos ${ }^{(9-11)}$. Staib (1984) refere a exposição de homens e animais na epidemiologia da criptococose ${ }^{(29)}$. No entanto, ainda não foi esclarecido o porquê da presença do fungo nesses excrementos, uma vez que o mesmo não é isolado do trato intestinal desses pombos. Existem poucos relatos de

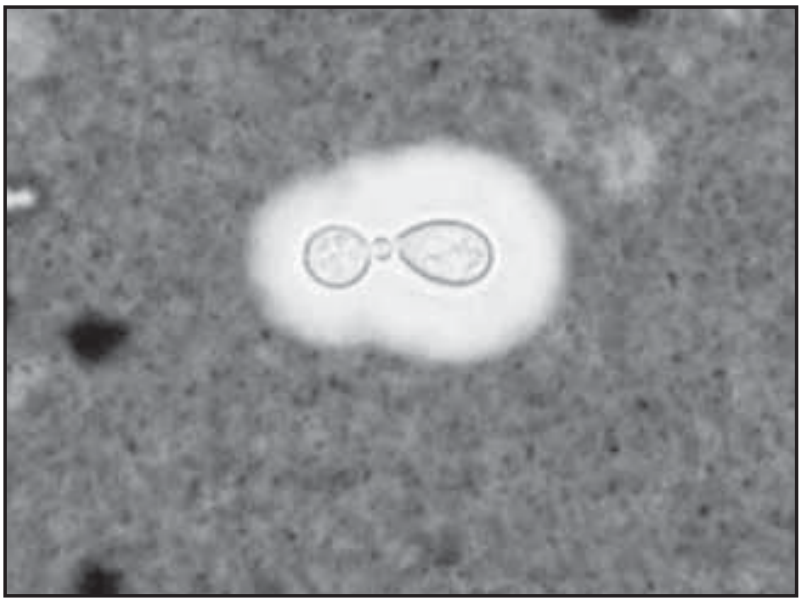

Figura 2 - Cápsula de C. neoformans delineado por tinta da China em aumento de 100x. 0 círculo externo representa a cápsula e a estrutura interna, a célula fúngica

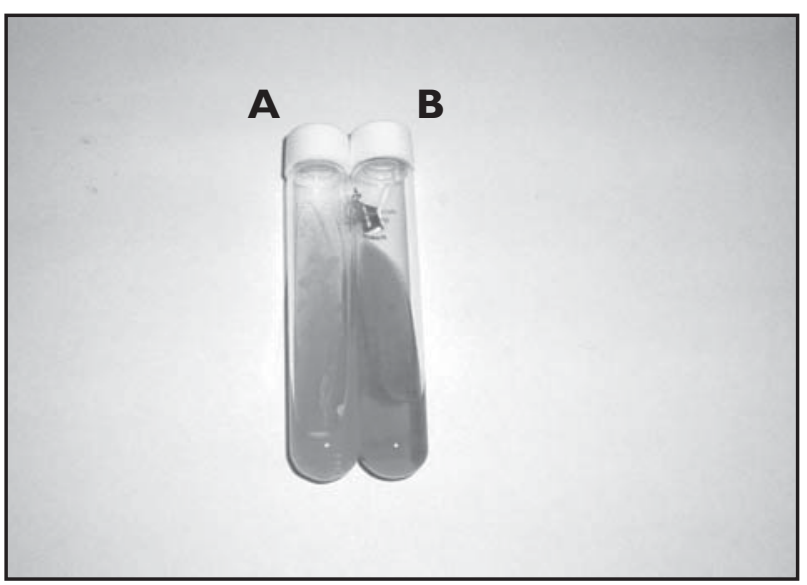

Figura 3 - Prova da urease em tubo A) prova negativa; B) prova positiva

criptococose em pombos ${ }^{(14,20)}$, porque eles são resistentes à invasão pelo fungo devido à sua elevada temperatura corporal. O isolamento do C. neoformans em excretas de psitacídeos também já foi relatado na literatura. Essas aves têm o hábito de raspar e fragmentar pedaços de madeira e galhos, onde as condições são favoráveis à sobrevivência e à multiplicação do C. neoformans ${ }^{(14,22)}$. Nossos resultados $100 \%$ positivos comprovam a contaminação das excretas dos pombos urbanos por $C$. neoformans na nossa cidade.

Foram observadas concentrações do fungo até mais de 10 mil unidades formadoras de colônias por grama de material semeado, confirmando a existência de fontes ambientais desse fungo. Nesses locais o fungo pode ser disperso no ar e, posteriormente, inalado. A inalação de grande quantidade dos propágulos poderá causar doença em indivíduos imunocompetentes e imunodeprimidos. 


\begin{tabular}{|c|c|c|c|c|c|}
\hline Local & Amostras & $\begin{array}{l}\text { Exame direto com } \\
\text { tinta da China }\end{array}$ & $\begin{array}{l}\text { Exame da colônia } \\
\text { com } \mathrm{KOH} 10 \%\end{array}$ & $\begin{array}{c}\text { Teste } \\
\text { da uréia }\end{array}$ & $\begin{array}{l}\text { Isolamento de } C \text {. } \\
\text { neoformans UFC } / g\end{array}$ \\
\hline \multirow[t]{3}{*}{ Praça 1} & 1 a 11 & Positivos & Positivos & Positivos & $\begin{array}{c}\text { Superior a } \\
10.000 U F C / g\end{array}$ \\
\hline & 12 & Negativo & Positivo* & Positivo & $4.500 \mathrm{UFC} / \mathrm{g}$ \\
\hline & 13 a 22 & Positivos & Positivos & Positivos & $\begin{array}{l}\text { Superior a } \\
10.000 \mathrm{UFC} / \mathrm{g}\end{array}$ \\
\hline Praça 2 & 23 a 38 & Positivos & Positivos & Positivos & $\begin{array}{c}\text { Superior a } \\
10.000 U F C / g\end{array}$ \\
\hline Praça 3 & 39 a 59 & Positivos & Positivos & Positivos & $\begin{array}{c}\text { Superior a } \\
\text { 10.000UFC/g }\end{array}$ \\
\hline Praça 4 & 60 a 72 & Positivos & Positivos & Positivos & $\begin{array}{c}\text { Superior a } \\
10.000 U F C / g\end{array}$ \\
\hline Praça 5 & 73 a 88 & Positivos & Positivos & Positivos & $\begin{array}{c}\text { Superior a } \\
10.000 \mathrm{UFC} / \mathrm{g}\end{array}$ \\
\hline
\end{tabular}

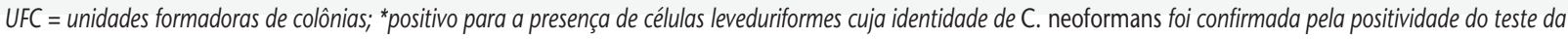
urease.

A doença pode disseminar-se e atingir o sistema nervoso central (SNC), em função do tropismo desse fungo pelo SNC. Atribui-se essa afinidade às concentrações ótimas de nutrientes (tiamina, ácido glutâmico, glutamina, dopamina, carboidratos e minerais) assimiláveis pelo fungo presentes no líquido cefalorraquidiano, e à fraca ou ausente resposta inflamatória do tecido cerebral( ${ }^{(19)}$.

Swinne et al. ${ }^{(30)}$ isolaram C. neoformans var. neoformans da poeira doméstica das amostras oriundas das residências dos pacientes com criptococose associada a AIDS. Em outro estudo foi demonstrada uma correlação significativa entre a existência de pombos próximas ao ambiente domiciliar e a probabilidade de contaminação dessas residências por $C$. neoformans. Conseqüentemente, pacientes com AIDS apresentavam risco aumentado de adquirir a doença quando residentes em domicílio positivo para o fungo ${ }^{(21,22)}$.

Mitchel e Perfect ${ }^{(20)}$ relataram que é grande o número de indivíduos com anticorpos circulantes após exposição e manejo de aves e hábitats contaminados com propágulos do C. neoformans. Porém, podem não desenvolver a doença. O C. neoformans infecta indivíduos imunocompetentes e imunodeprimidos, com variações nos achados clínicos e radiológicos. O fator predisponente mais comum é a imunossupressão relacionada com alterações da função das células $T$.

\section{Conclusão}

Os resultados obtidos neste estudo permitiram verificar a elevada prevalência ambiental do agente fúngico C. neoformans nos pombos que habitam as praças localizadas na cidade de Porto Alegre, sendo verificado que em todas as praças onde as coletas foram realizadas foi encontrado número semelhante de propágulos por grama de fezes, permitindo assim afirmar que, independente da localização, não houve diferença significativa na contaminação ambiental verificada. Estes achados trazem à luz a questão de minimizar o risco de exposição a microfocos de C. neoformans em locais de circulação pública e em domicílios de pacientes imunodeprimidos através da vigilância das condições de higiene e limpeza de excretas, aeração, iluminação e ventilação adequadas, bem como monitorização de locais de risco. A presença do C. neoformans em $100 \%$ das amostras pesquisadas neste estudo sugere estudos subseqüentes para monitorar essa freqüência e determinar a variedade do $C$. neoformans de maior prevalência em Porto Alegre. 


\section{Referências}

I.ALSPAUGH, J.A.; PERFETC, J. R.; HEITMAN, J. Signal transduction pathways regulating differentiaton and pathogenicity of Cryptococcus neoformans. Fungal Genet Biol, v. 25, n. 8, p. I- 14, 1998.

2.AOKI, S. et al. Extracellular proteolytic of Cryptococcus neoformans. Mycopathologia, v. 128, p. 143-50, 1994.

3. BUCHANAN, K. L.; MURPHY, J. W. What makes Cryptococcus neoformans a pathogen? Emerg Infect Dis, v. 4, n. I, p. 7I-83, 1998.

4. CASADEVALL, A.; PERFECT, J. R. Cryptococcus neoformans. Washington, DC:ASM Press, 1998.

5. COX, G. M. et al. Extracellular phospholipase activity is a virulence factor for Cryptococcus neoformans. Mol Microbiol, v. 39, n. 2, p. 166-75, 2001.

6. DIAZ, M. R. et al. Molecular sequence of the intergenic spacer associated with rDNA of the two varieties of the pathogenic yeast Cryptococcus neoformans. Syst Appl Microbiol (in press), 2001.

7. ELLIS, D. H.; PFEIFFER, T. J. Ecology: life and infectious propagule of Cryptococcus neoformans. Lancet, v. 336, n. 9, p. 923-5, 1990.

8. ELLIS, D. H.; PFEIFFER,T.J.The ecology of Cryptococcus neoformans. Eur J Epidemiol, v. 8, n. 6, p. 321-5, 1992.

9. EMMONS, C.W. Natural occurrence of opportunistic fungi. Lab Invest, v. I I, n. 4, p. I026-32, 1962.

10. Emmons, C.W. Prevalence of Cryptococcus neoformans in pigeon habitats. Public Health Rep, v. 75, n. 5, p. 362-4, 1960.

I I.EMMONS, C.W. Saprophytic sources of Cryptococcus neoformans associated with the pigeon (Columba livia). Am J Hyg, v. 62, n. 9, p. 227-32, 1955.

12. HAMILTON, J. D.; HOLDOM, M. D. Antioxidant systems in the pathogenic fungi of man and their role in virulence. Med Mycol, v. 37, p. 175-89, 1999.

13. JACOBSON, E. S. Pathogenic roles for fungal melanins. Clin Microbiol Rev, v. 13, n. 2, p. 708-17, 2000.

14. KWON-CHUNG, K. J.; BENNETT, J. E. Cryptococcosis. In: CAMILO-COURA, L.; Febiger (eds). Medical mycology. Philadelphia, 1992. p. 397-446

I5. KWON-CHUNG, K. j; BENNETT,J. E. Epidemiologic differences between the varieties of Cryptococcus neoformans. Am J Epidemiol, v. 120, n. 6, p. 123-30, 1984.

16. LAZÉRA, M. S. et al. Possible primary ecological niche of Cryptococcus neoformans. Med Mycol, v. 38, n. 3, p. 379-83, 2000.

17. LAZÉRA, M. S. et al. Cryptococcus neoformans var. gattii: evidence for a natural habitat related to decaying wood in a pottery tree hollow. Med Mycol, v. 36, n. I I, p. I 19-22, 1998.

I8. LENGELER, K. B.; COX, G. M.; HEITMAN, J. Serotype AD strains of Cryptococcus neoformans are diploid or aneuploid and are heterozygous at the mating-type locus. Infect Immun, v. 69, p. I15-22, 2001 .

19. LEVITZ, S. M.The ecology of Cryptococcus neoformans and the epidemiology of Cryptococcosis. Rev Infect Dis, v. I3, n. 2, p. ||63-9, 199|.
20. MITCHEL,T.G.;PERFECT,J. R. Cryptococcosis in the era of AIDS100 years after the discovery of Cryptococcus neoformans. Clin Microbiol Rev, v. 8, n. 7, p. 5 15-48, 1995.

21. PASSONI, L. F. C. et al. Cryptococcus neoformans isolated from human dwellings in Rio de Janeiro, Brazil: an analysis of domestic environment of AIDS patients with and without cryptococcosis. Med Mycol, v. 36, n. 9, 305- I I, 1998.

22. PASSONI, L. F. C.Wood, animals and human beings as reservoir for human Cryptococcus neoformans infection. Rev Iberoam Micol, v. 16, n. 6, p. 77-81, 1999.

23. PERFECT, J. R. et al. Cryptococcus neoformans: virulence and host defences. Med Micol, v. 36, suppl. I , p. 79-88, 1998.

24. POLAK, A. Melanin as a virulence factor in pathogenic fungi. Mycoses, v. 33, n. 5, p. 215-8, 1989.

25. RIPPON, J.W. Medical mycology. In: The pathogenic fungi and pathogenic actinomycetes. New York: WB Saunders, 1988. p. 582-609.

26. ROSENBAUM, R.; GONÇALVES,A.J. R. Clinical epidemiological study of I7| cases cryptococcosis. Clin Infect Dis, v. I 8, n. 3, p. 369-80, 1994.

27. STAIB, F. Cryptococcus neoformans and cryptococcosis. Peculiarities and challenge: opening lecture of Second International Conference on Cryptococcus and Cryptococcosis. Milan (Italy), September 19-23, 1993. Journal Mycology Medical, v. 4, n. 7, p. 56-60, 1994.

28. STAIB, F. Saprophytic life of Cryptococcus neoformans. Ann Soc Belg Méd Trop, v. 44, n. 6, p. 61 I -8, 1964.

29. STAIB, F:; SCHUULTZ-DIETERJCH, J. Cryptococcus neoformans in fecal matter of birds kept in cages: control of Cryptococcus neoformans habitats. Zentralblatt für Bakteriologie und Parsitenkunde, v. 174, n. 8, p. 79-186, 1984.

30. SWINNE, D.; BAUVERNS, L.; DESMET, P. More information about the natural habitat of Cryptococcus neoformans. Newsletter International Society for Human and Animal Mycology, v. 60, n. 9, p. 4, 1992.

31. WICLES, B. L. et al. Dimorphism and haploid fruiting in Cryptococcus neoformans: association with the a-mating type. Proceeding of the National Academy of Science, v. 93, n. 4, p. 7327-31, 1996. 